\title{
An Electrochemical Impedance Spectroscopic Study of the Passive State on AISI 304 Stainless Steel
}

\author{
A. Fattah-alhosseini, S. Taheri Shoja, B. Heydari Zebardast, and P. Mohamadian Samim \\ Faculty of Engineering, Bu-Ali Sina University, Hamedan 65178-38695, Iran \\ Correspondence should be addressed to A. Fattah-alhosseini, a.fattah@basu.ac.ir
}

Received 15 December 2010; Accepted 7 January 2011

Academic Editor: Sheng S. Zhang

Copyright (๑) 2011 A. Fattah-alhosseini et al. This is an open access article distributed under the Creative Commons Attribution License, which permits unrestricted use, distribution, and reproduction in any medium, provided the original work is properly cited.

\begin{abstract}
The passivity and protective nature of the passive films are essentially related to ionic and electronic transport processes, which are controlled by the optical and electronic properties of passive films. In this study, the electrochemical behavior of passive films anodically formed on AISI 304 stainless steel in sulfuric acid solution has been examined using electrochemical impedance spectroscopy. AISI 304 in sulphuric acid solution is characterized by high interfacial impedance, thereby illustrating its high corrosion resistance. Results showed that the interfacial impedance and the polarization resistance $\left(R_{\text {pol }}\right)$ initially increase with applied potential, within the low potential passive. However, at a sufficiently high potential passive $(E>0.4 \mathrm{~V})$, the interfacial impedance and the polarization resistance decrease with increasing potential. An electrical equivalent circuit based on the impedance analysis, which describes the behavior of the passive film on stainless steel more satisfactorily than the proposed models, is presented.
\end{abstract}

\section{Introduction}

Stainless steel possesses high corrosion resistance due to its ability to spontaneously form stable passive oxides in air and aqueous solutions. These oxides, which in many cases are no thicker than a few nanometers [1-3], act as a reactivity barrier between the metal and the environment. The electrochemical polarization method, including anodic passivation, enhances the preferential dissolution of iron into solution and the enrichment of chromium in the passive film, and hence this method is effective for increasing stability, compaction, and corrosion resistance of the passive films $[4,5]$. The corrosion reaction rate, that is, the anodic current density of anodic films, is lowered by several orders of magnitude than that of naturally grown oxide films. The chemical composition, the structure, and the thickness of electrochemically formed passive films on stainless steel change not only with environment but especially with passivation potential [6-9].

Over the recent years, most of the modern descriptions of passive films are based on the concepts presented by Macdonald and coworkers [10-15] in the point defect model (PDM). The PDM assumes that the transport of matter through the film takes place via ionic point defects. This transport is necessary for any growth of the film. The presence of point defects also provides a path for the cations formed from the substrate metal to pass through the film into the solution. Point defects are formed and annihilated in reactions proceeding at the metal/film and film/solution interfaces. The rates of these reactions and of the defect transport determine to a great extent the electrical and electrochemical properties of the film [16-18].

Electrochemical impedance spectroscopy (EIS) has been widely used for studying the electrochemical mechanisms occurring on the electrodes. EIS data can be used to establish an equivalent electrical circuit model for the electrochemical processes of electrodes. The various elements in this equivalent circuit are related to the metal/film and film/solution interfaces and the phenomena occurring inside the passive film $[19,20]$. EIS measurements make it possible to obtain some information on the mechanism, establishing a theoretical transfer function and developing the passive film growth model $[21,22]$.

AISI 304 stainless steel is the most popular alloy, used extensively because of its good corrosion resistance; its passive films have been the subject of many investigations. 
In spite of the relatively large amount of research on the electrical properties of passive films anodically formed, however, few papers have been published on a systematic study of the impedance behavior. The great complexity of the metal/passive film/electrolyte system of stainless steels makes the clarification of the passive film difficult. In this work, EIS measurements were made in a large range of frequencies in order to get more information on the passive film electrochemically grown on AISI 304 stainless steel/solution properties.

\section{Experimental Procedures}

Specimens were cut from $1 \mathrm{~cm}$ diameter rods of AISI 304 stainless steel; the chemical composition (\%, wt.): Cr 18.1, Ni 8.7, Mn 1.1, Si 0.47, C 0.08, S 0.002, and balance Fe. The samples were placed in stainless steel sacks and were annealed in inert environment (Ar gas) to eliminate the cold work effect due to cutting process. The annealing was preformed at $1050^{\circ} \mathrm{C}$ for $90 \mathrm{~min}$ followed by water quenching. The pretreatment applied on specimens consisted of mechanical polishing using emery papers up to 1200 grade, degreasing and rinsing in distilled water. A three-electrode cell featuring a Pt counter electrode and a saturated calomel electrode (SCE) was employed. All the potential values in the text are relative to the SCE. The solution $\left(0.5 \mathrm{M} \mathrm{H}_{2} \mathrm{SO}_{4}\right)$ was prepared from analytical grade $97 \% \mathrm{H}_{2} \mathrm{SO}_{4}$ and distilled water. Prior to each experiment, the working electrode was catholically polarized at $-1.2 \mathrm{~V}$ for $5 \mathrm{~min}$.

Impedance investigations were performed using an EG\&G Model 273A potentiostat/galvanostat controlled by a personal computer at ambient temperature $\left(23-25^{\circ} \mathrm{C}\right)$. Passive films on AISI 304 stainless steel were formed potentiostatically at DC potentials selected based on the passive region of anodic curve for $1 \mathrm{~h}$ and then EIS measurements were done. Each electrochemical measurement was repeated at least three times. An excitation voltage of $10 \mathrm{mV}$ (peakto-peak) and an applied frequency ranging from $100 \mathrm{kHz}$ to $10 \mathrm{mHz}$ have been used. All the potential values in the text are relative to the SCE. For EIS data modeling and curve-fitting method, Z-View2 impedance software "Equivalent Circuit" was used. This program is based on the method of nonlinear least squares, which allows nonideal electrochemical behavior to be modeled.

\section{Results and Discussion}

3.1. Experimental Results. The electrochemical behavior of the anodic passive films on AISI 304 stainless steel in $0.5 \mathrm{M}$ $\mathrm{H}_{2} \mathrm{SO}_{4}$ has been evaluated by means of impedance measurements. For this purpose, passive films on stainless steel electrode were formed potentiostatically at DC potentials selected based on the passive region of anodic curve for $1 \mathrm{~h}$ and then EIS measurements were done. The potential of $0.8 \mathrm{~V}$ corresponds to the upper limit of the passive region, which also corresponds to the beginning of the transpassive region. Typical Nyquist and Bode plots for anodic oxide films are presented in Figure 1. Bode plots have been added

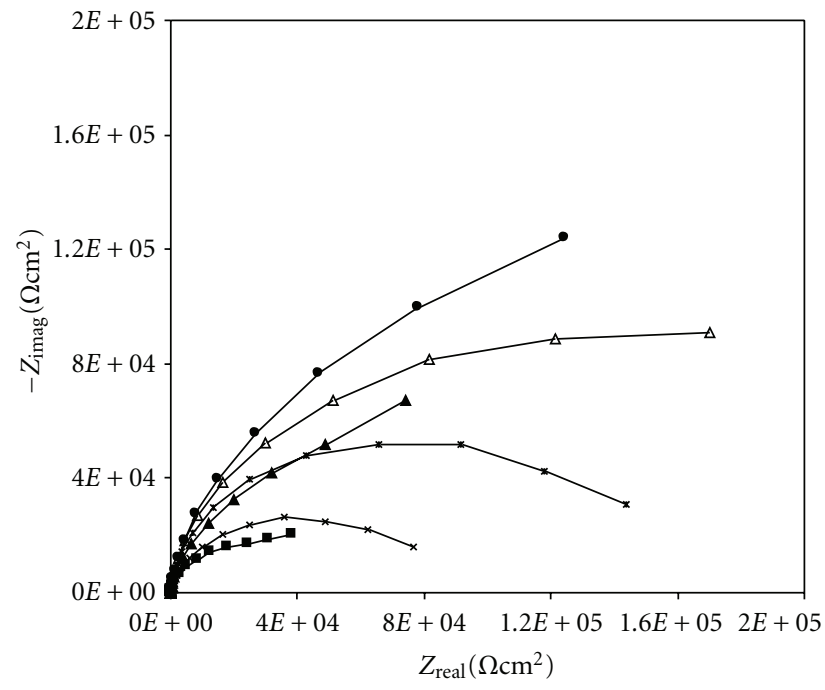

(a)

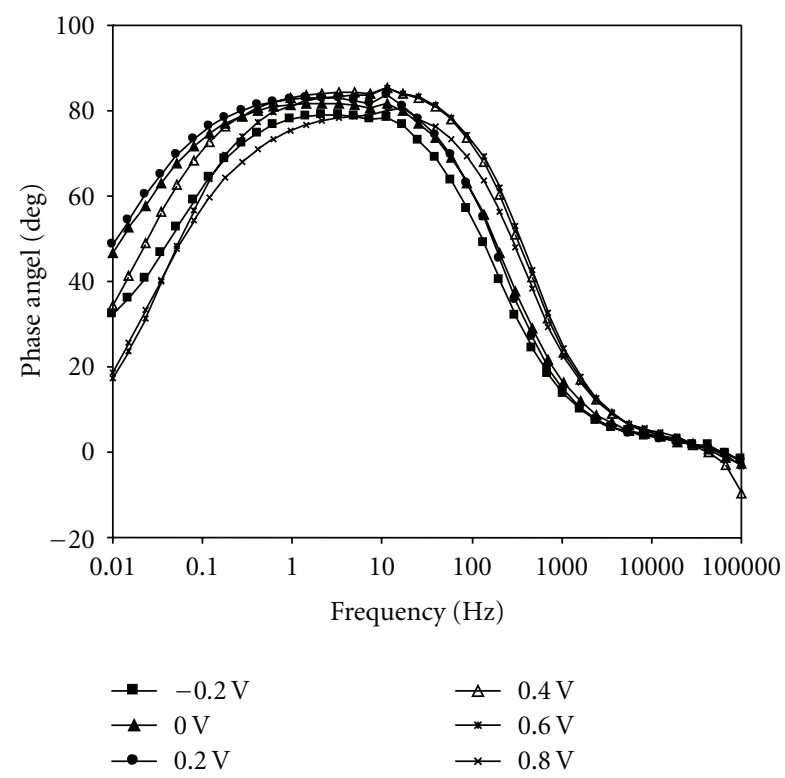

(b)

FIGURE 1: Impedance spectra for AISI 304 stainless steel in $0.5 \mathrm{M}$ $\mathrm{H}_{2} \mathrm{SO}_{4}$ solution as a function of film formation potential: (a) Nyquist plots and (b) Bode plots.

for the representation of the impedance spectra because the magnitude of the impedance at low frequencies is several orders of magnitude higher than that at high frequencies, and thus high-frequency features are difficult to discern in a Nyquist plot. In the frequency range of measurement, all impedance spectra have the same features.

Figure 2 indicates that the impedance magnitude at low frequencies initially increases with film formation potential, within the low passive potential. However, at a sufficiently high passive potential $(E>0.4 \mathrm{~V})$ the impedance magnitude decreases with increasing potential. The high impedance values in this low-frequency region can be associated with the presence of the barrier layer of the passive film. 


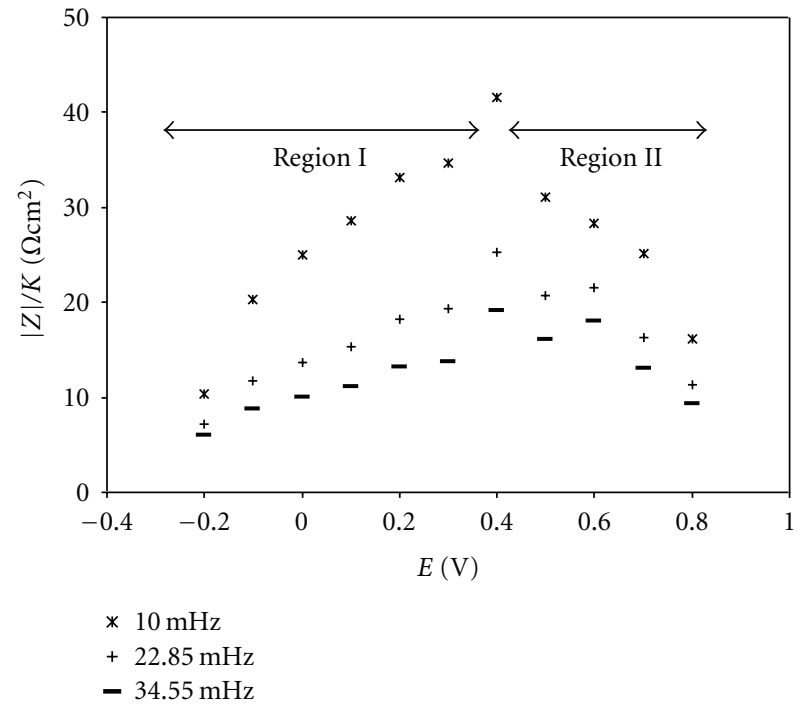

FIGURE 2: Effect of film formation potential on impedance magnitude of AISI 304 stainless steel in $0.5 \mathrm{M} \mathrm{H}_{2} \mathrm{SO}_{4}$ at low frequencies.

3.2. The Physical and Mathematical Models of the Metal/Passive Film/Solution System. For many years, a great number of mechanisms and models have been put forward through the research and analysis of the EIS of different systems. Among these models, the six main ones are as follows.

Model $A$. The interface resistance $R$ and the capacitance $C$ are simply paralleled to represent the passive electrode system [23-26].When measuring the impedance of the actual system, the obtained capacitance sometimes may deviate from the "pure capacitance". Therefore, a constant phase element $(Q)$ is introduced for the fitting to replace capacitor $C$. In Figure 3(a), $R_{S}$ is the uncompensated solution resistance; $R_{1}$ and $Q_{1}$ are the interface resistance and the interface constant phase element, respectively. The mathematical expression of the impedance of the electrode system in this model is

$$
Z=R_{S}+\frac{1}{1 / R_{1}+Y_{0}(j \omega)^{n}} .
$$

The impedance of the constant phase element $Q$ is presented by

$$
Z_{Q}=\left[Y_{0}(j \omega)^{n}\right]^{-1}
$$

$Y_{0}$ and $n$ are two parameters of $Q$. When $n=1$, it means that $Q$ is equivalent to a pure capacitor and $Y_{0}=C$.

Model B. It is believed that the impedance of the passive films of metals comes from the migration of metal and oxygen vacancies within the film. Macdonald and coworkers propose the point defect model about the growth and destruction of the passive film. According to this model, the process of migration of metal vacancies and oxygen vacancies within the passive film has the form of Warburg impedance. When the oxygen vacancies are dominant in the passive film, the impedance of the film $Z_{f}=\sigma_{0} \omega^{-1 / 2}(1-j)$. Figure 3(b) shows the equivalent circuit of this model; here $R_{1}$ is the charge transfer resistance [27]. The mathematic expression of the impedance of this electrode system is

$$
Z=R_{S}+\frac{1}{Y_{0}(j \omega)^{n}+1 /\left(R_{1}+Z_{D}\right)} .
$$

Model C. A constant phase element $\left(Q_{2}\right)$ is used to represent the transfer of the charged particles within the passive film, shown in Figure 3(c). It is believed that the passive film has capacitive characters. Jamnik et al. think that, in the impedance complex plane diagram, the diffusion activities of the charged particles in a solid are not reflected as a $45^{\circ}$ sloped straight line but as a line that approximates $90^{\circ}$ which reflects the capacitive characters of the electrode [28]. The mathematic expression of the impedance of the electrode system is

$$
Z=R_{S}+\frac{1}{1 / R_{1}+Y_{01}(j \omega)^{n_{1}}}+\frac{1}{Y_{02}(j \omega)^{n_{2}}} .
$$

Model D. Two R//Q parallel circuits are used, to represent the electrochemical activities of the passive film and the film/solution interface, respectively, (Figure 3(d)) [29]. In this figure, $R_{1}$ and $Q_{1}$ are the charge transfer resistance and the double layer capacitance, respectively. $R_{2}$ and $Q_{2}$ are the film resistance and the film capacitance, or the resistance and capacitance of the space charge layer, respectively. The mathematical expression of the impedance of the electrode system in this model is

$$
Z=R_{S}+\frac{1}{1 / R_{1}+Y_{01}(j \omega)^{n_{1}}}+\frac{1}{1 / R_{2}+Y_{02}(j \omega)^{n 2}} .
$$

Model E. Figure 3(e) shows a graphical representation of the electrochemical system and the equivalent circuit [30]. $C_{1}$ and $R_{1}$ represent the capacitive and resistive contributions of the passive film/metal interface, $C_{P}$ and $R_{P}$ represent the bulk passive film, $Q$ and $R_{2}$ represent the solution/passive film interface, and $R_{S}$ is the uncompensated solution resistance. The mathematical expression of the impedance of the electrode system in this model is

$$
\begin{aligned}
Z= & R_{S}+\frac{1}{1 / R_{1}+Y_{01}(j \omega)^{n_{1}}}+\frac{1}{1 / R_{P}+C_{P}(j \omega)^{n}} \\
& +\frac{1}{1 / R_{2}+C_{2}(j \omega)^{n}} .
\end{aligned}
$$

Model F. Figure 3(f) shows a graphical representation of the electrochemical system and the equivalent circuit [31]. The equivalent circuit is a combination of three branches, including the uncompensated solution resistance, $R_{S} \cdot R_{\mathrm{ct}}$ and $Q_{\mathrm{dl}}$ are the charge-transfer resistance of the interfacial reaction and the double-layer capacitance. $R_{P}$ and $Q_{P}$ are related to the electronic charging in the passive oxide film. $Z_{D}$ represents the impedance diffusion, which can be related to ionic defect transport through the passive film. $R_{1}$ and 


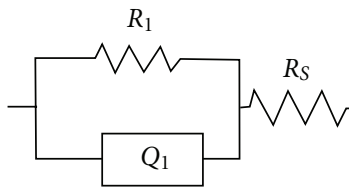

(a)

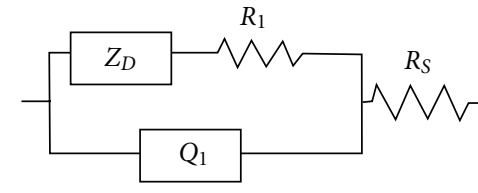

(b)

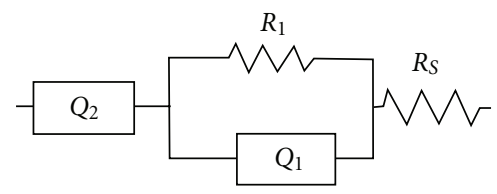

(c)

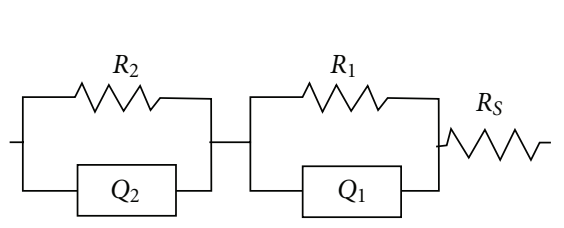

(d)

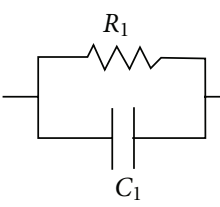

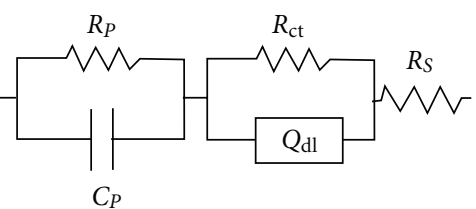

(e)

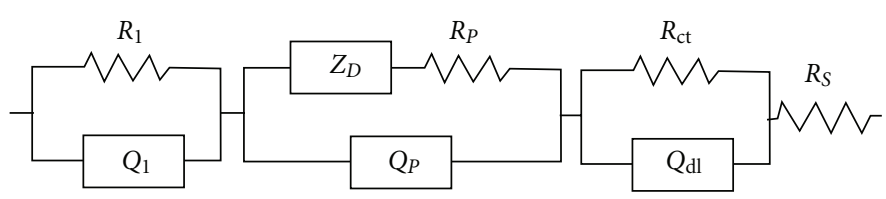

(f)

Figure 3: Physical models for metal/passive film/solution system: (a) Model A, (b) Model B, (c) Model C, (d) Model D, (e) Model E, and (f) Model F.

$Q_{1}$ indicate the contribution of surface states. According to Cahan et al. [30], in some passivation conditions an excess proton creates a corresponding $\mathrm{Fe}^{2+}$ and a deficient proton causes an equivalent $\mathrm{Fe}^{3+}$ in the film, and these ions play the role of surface states. The mathematical expression of the impedance of the electrode system in this model is

$$
\begin{aligned}
Z= & R_{S}+\frac{1}{1 / R_{\mathrm{ct}}+Y_{0 \mathrm{dl}}(j \omega)^{n_{\mathrm{dl}}}}+\frac{1}{1 /\left(R_{P}+Z_{D}\right)+Y_{0 P}(j \omega)^{n_{P}}} \\
& +\frac{1}{1 / R_{1}+Y_{01}(j \omega)^{n_{1}}} .
\end{aligned}
$$

The impedance of diffusion is given by

$$
Z_{D}=R_{D} \frac{\tanh \left(j \omega\left(\delta^{2} / D\right)\right)^{n^{\prime}}}{\left(j \omega\left(\delta^{2} / D\right)\right)^{n^{\prime}}}
$$

where $R_{D}$ is the diffusion resistance, $\delta$ is the effective diffusion thickness, $D$ is the effective diffusion coefficient, and $n^{\prime}$ is the generalized finite Warburg exponent.

3.3. The Fitting Results. Figure 4 shows that the fitting results of typical Nyquist plots for passive films on AISI 304 electrodes were formed potentiostatically at $0.2 \mathrm{~V}$ using the five models. It is found that the fitting errors of Models A, B, C, and D are relatively high. In Model A, the EIS is corresponding to a capacitive loop. When fitting the data, the fitting error increases remarkably. In Model B, diffusion process occurs at low frequency and has a form of Warburg impedance. When fitting with this model, large errors occur in the low-frequency region. Therefore, Models A and B are not suitable for this system.

In Model C, $R_{1}$ is the charge transfer resistance. $Q_{1}$ and $Q_{2}$, respectively, reflect the double-layer capacitance and

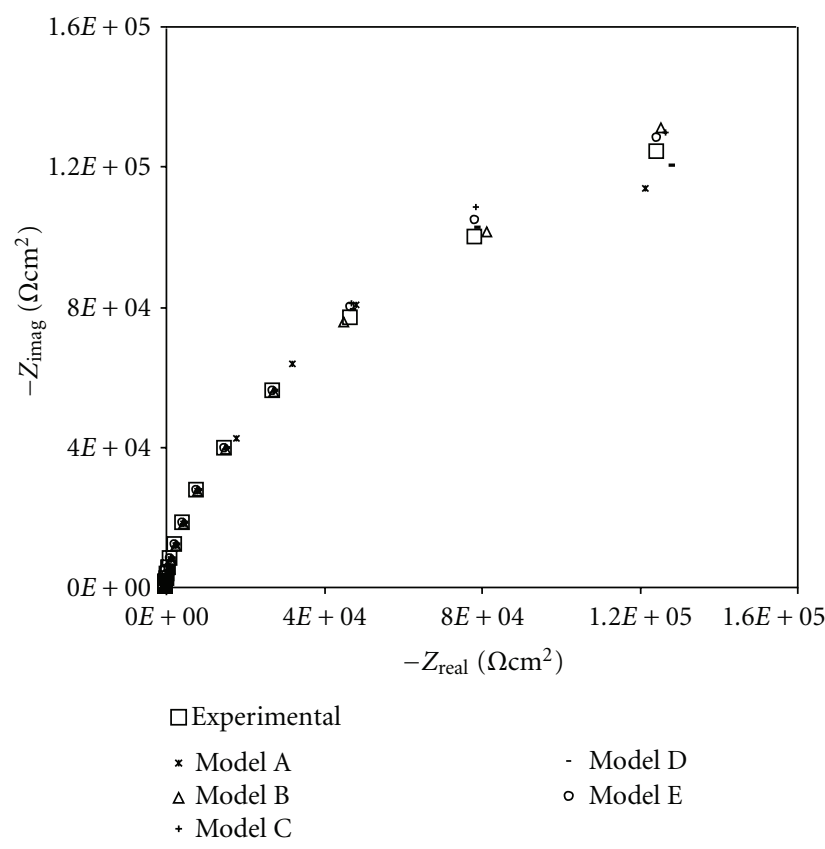

FIGURE 4: The fitting results of typical Nyquist plots for passive films on AISI 304 electrodes were formed potentiostatically at $0.2 \mathrm{~V}$ using the five models.

the substance transfer processes in the passive film. From the physical point of view, it is not reasonable to represent the substance transfer within the passive film simply by a capacitor. Model D consists of two (R-Q) parallel circuits, which represent the contribution of the interfacial reaction and a passivating film. When fitting with this model, large errors occur in the low-frequency region and no significant variations of the different electrical-circuit element were 


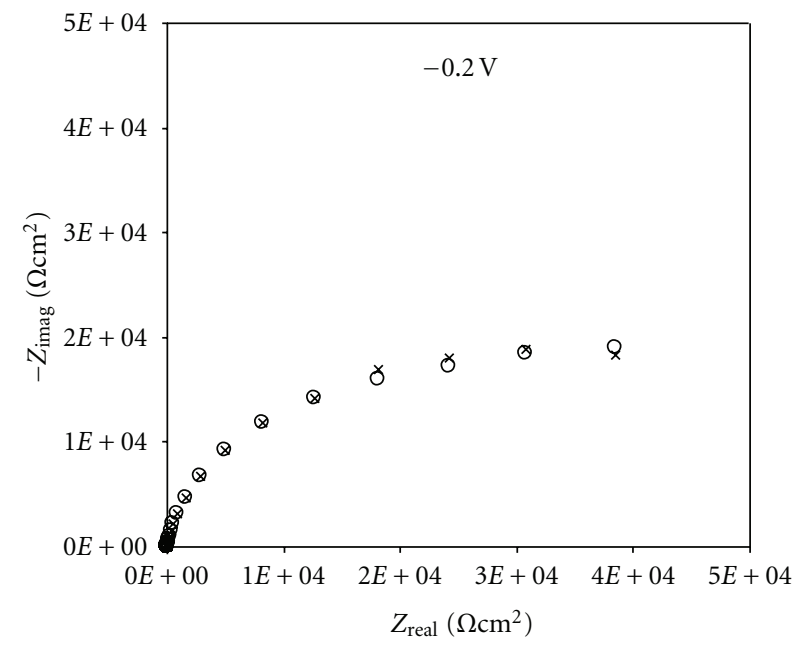

(a)

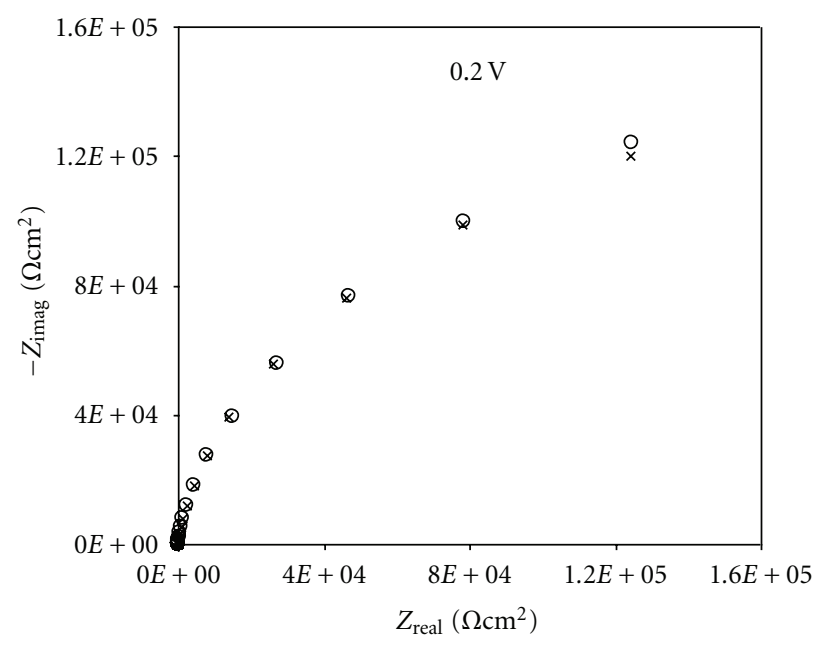

(c)

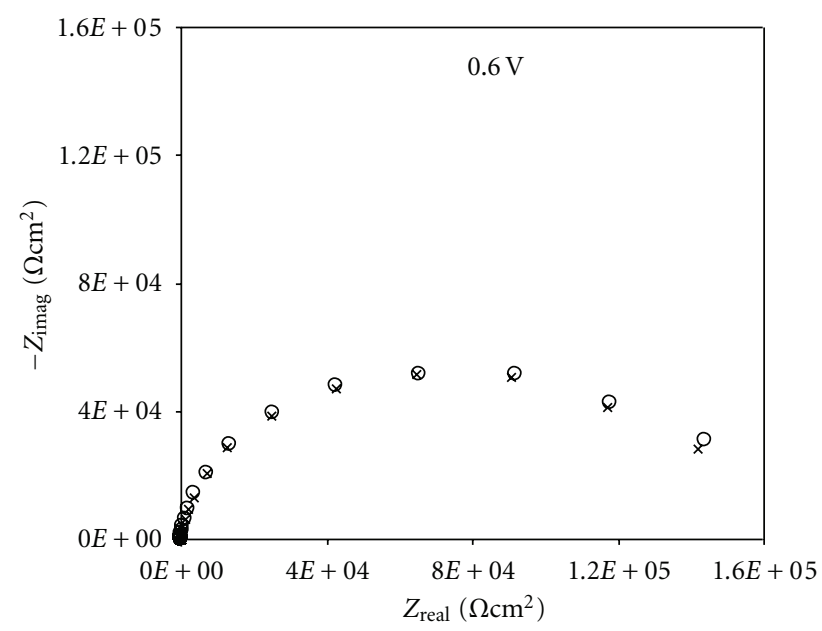

O Experimental

$\times$ Simulated

(e)

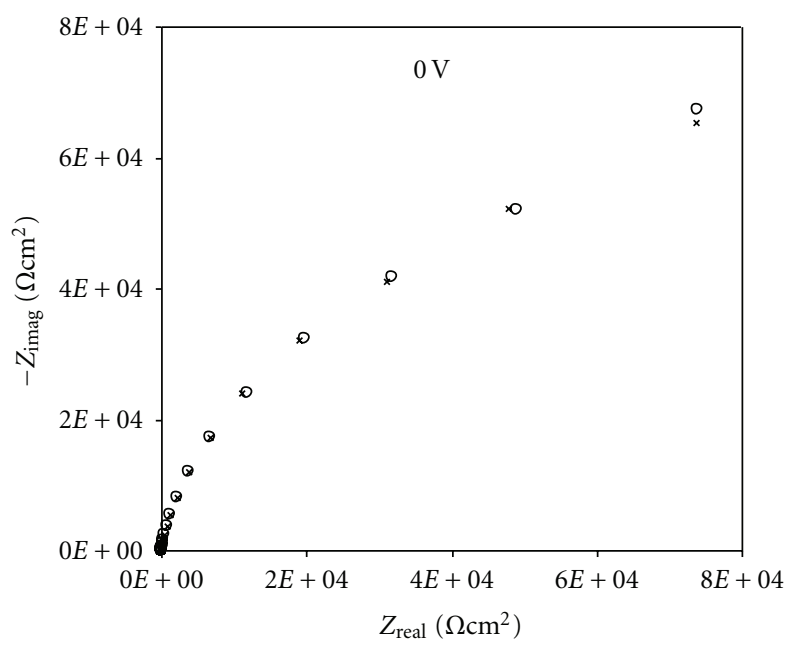

(b)

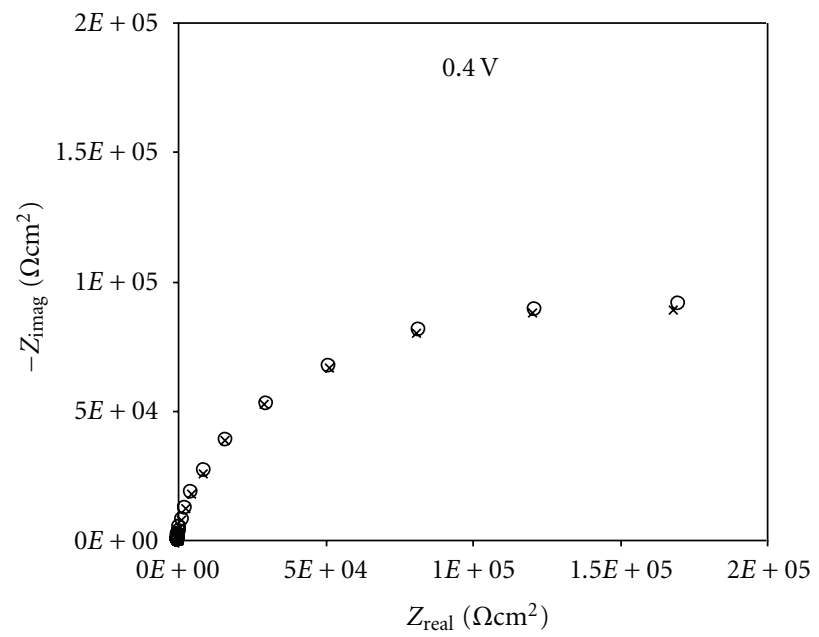

(d)

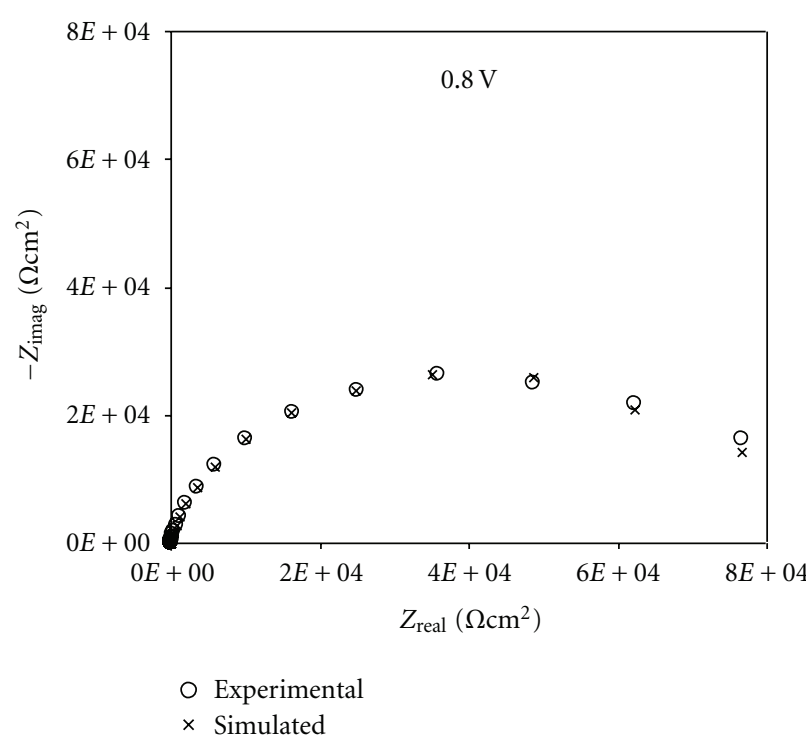

(f)

FigurE 5: Nyquist plots for AISI 304 stainless steel in $0.5 \mathrm{M} \mathrm{H}_{2} \mathrm{SO}_{4}$ and as a function of potential showing a comparison between the experimental and simulated data. 
TABLe 1: Passive element values for the equivalent circuit of model F obtained from the fitting procedure of types.

\begin{tabular}{lccccccccccc}
\hline$E / \mathrm{V}$ & $\begin{array}{c}R_{1} \\
\Omega \mathrm{cm}^{2}\end{array}$ & $\begin{array}{c}Y_{01} \\
\mu \mathrm{Fcm} \mathrm{cm}^{-2}\end{array}$ & $n_{1}$ & $\begin{array}{c}R_{P} \\
\mathrm{k} \Omega \mathrm{cm}^{2}\end{array}$ & $\begin{array}{c}Y_{0 P} \\
\mu \mathrm{Fcm}^{-2}\end{array}$ & $n_{2}$ & $\begin{array}{c}R_{D} \\
\mathrm{k} \Omega \mathrm{cm}^{2}\end{array}$ & $\delta^{2} / D$ & $\begin{array}{c}R_{\mathrm{ct}} \\
\mathrm{k} \Omega \mathrm{cm}^{2}\end{array}$ & $\begin{array}{c}Y_{01} \\
\mu \mathrm{Fcm}\end{array}$ \\
\hline-0.2 & 1.87 & 213.44 & 0.78 & 3.37 & 498.25 & 0.95 & 10.80 & 4.42 & 68.43 & 121.03 & 0.89 \\
0.0 & 1.99 & 317.53 & 0.73 & 7.52 & 318.42 & 0.88 & 4.29 & 4.44 & 78.94 & 129.89 & 0.93 \\
0.2 & 2.16 & 314.71 & 0.69 & 9.69 & 191.95 & 0.85 & 1.94 & 4.96 & 162.02 & 66.53 & 0.99 \\
0.4 & 1.38 & 33.66 & 0.94 & 26.83 & 78.14 & 0.90 & 1.70 & 4.13 & 146.39 & 54.83 & 0.99 \\
0.6 & 1.15 & 6.44 & 0.99 & 95.51 & 27.99 & 0.94 & 1.09 & 3.86 & 17.75 & 734.29 & 0.99 \\
0.8 & 1.24 & 0.91 & 0.99 & 10.02 & 90.79 & 0.86 & 2.10 & 3.86 & 54.31 & 72.568 & 0.95 \\
\hline
\end{tabular}

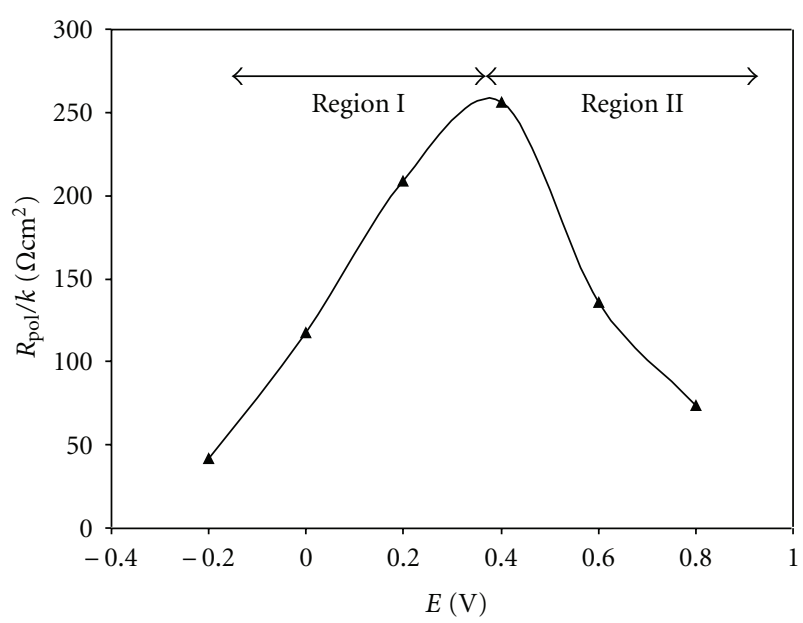

FIGURE 6: Effect of potential on polarization resistance of AISI 304 stainless steel in $0.5 \mathrm{M} \mathrm{H}_{2} \mathrm{SO}_{4}$.

found. Therefore, Models C and D are not suitable for this system either. When fitting with Model E, small errors occur in the low-frequency region.

The above six models were used to fit the impedance data obtained; it was found that the fitting results of model F are suitable to the actual passivation process. When fitting our theoretical electrical-equivalent circuit, a value of chiquadrate $\left(\chi^{2}\right)$ of approximately $10^{-4}$ was found and the fitting errors were quite small. Figure 5 shows in all cases that the correlation between experimental data and simulated data is very good.

The Bode plots and admittance plots (not shown) also displayed an acceptable agreement between experimental and simulated data, thereby validating the selected equivalent circuit model. Table 1 summarizes the values of the circuit parameters obtained from the best fit with the experimental impedance diagrams.

Contrary to charge-transfer resistance $\left(R_{\mathrm{ct}}\right)$, which does not vary significantly with film formation potential, film resistance $\left(R_{P}\right)$ varies with film formation potential. $R_{P}$ increases considerably with film formation potential. This increase of $R_{P}$ is accompanied by a decrease of $Y_{0 P}$ at every electrode potential, reflecting the growth and the thickening of the passive film or the decrease in the amount of charge carriers in the film. One can notice the continuous decrease of $R_{P}$ when the film formation potential increases and its highest value at films formed at $0.6 \mathrm{~V}$. These results may be related to the presence and the competition of two kinds of oxides, chromium and iron. At low potentials (potentials lower than the transpassive potential of chromium), passive films are more enriched with chromium, making the films more protective. At high potential in the passive range, chromium decreases continuously and iron increases progressively and hence the protective effect reduces.

The values of the exponent $n_{2}$ obtained by fitting our EIS data were between 0.85 and 0.95 , which points to a considerable passive film surface homogeneity; therefore, the constant phase element can be assumed to correspond to capacitive behavior, while the values of $n_{1}$ and $n_{3}$ obtained can be associated with a distribution of the relaxation times as a result of heterogeneities present at the interfaces and static disorders such as porosity [32].

The impedance of diffusion is independent of film formation potential. Defect transport is primarily due to migration under the influence of the electric field, and because the field strength is postulated to be independent of the applied potential in the point defect model, the impedance should be insensitive to the film formation potential [33].

The significant variation of $R_{1}$ with the film formation potential is characteristic for uniform distribution of surfacestates. The values of $R_{1}$ initially increased with film formation potential in the region I. At a sufficiently high potential $(E>0.4 \mathrm{~V})$, which is close to the onset of the transpassive state (Region II), $R_{1}$ is observed to decrease with increasing formation potential. Moreover, the change of $Y_{01}$ shows a similar tendency. The surface-state capacitance decreases with increasing film formation potential. This decrease can be correlated either with a decrease of surface-state concentration or with a decrease of the active area available for their interaction.

The polarization resistance was taken to be the sum of $R_{1}, R_{P}, R_{D}$, and $R_{2}$. Figure 6 shows the variation of polarization resistance with the film formation potential. The polarization resistance $\left(R_{\mathrm{pol}}\right)$ initially increased with film formation potential in the region I. This is due to the establishment of the passive oxide layer. At a sufficiently high potential $(E>0.4 \mathrm{~V})$, which is close to the onset of the transpassive state (Region II), the polarization resistance is observed to decrease with increasing potential. It has been reported that this is due to the oxidative ejection of $\mathrm{Cr}(\mathrm{VI})$ from the passive film. 


\section{Conclusion}

(1) The impedance data obtained for AISI 304 in sulphuric aid solution were adequately represented by an equivalent electrical circuit model, comprising two $R / / Q$ elements in series with a $Z_{D}-R / / Q$ and an uncompensated solution resistance.

(2) The interfacial impedance and polarization resistance initially increased with applied potential. At a sufficiently high potential $(E>0.4 \mathrm{~V})$, which is close to the initiation of the transpassive state, the interfacial impedance and polarization resistance were observed to decrease with increasing potential. The polarization resistance of AISI 304 stainless steel is of the order of $10^{3} \mathrm{k} \Omega \mathrm{cm}^{2}$, commensurate with its high corrosion resistance.

\section{References}

[1] E. Cho, S. Ahn, and H. Kwon, "Effects of EDTA on the electronic properties of passive film on $\mathrm{Fe}-20 \mathrm{Cr}$ in $\mathrm{pH} 8.5$ buffer solution," Electrochimica Acta, vol. 50, no. 16-17, pp. 3383-3389, 2005.

[2] S. Fujimoto, S. Kawachi, T. Nishio, and T. Shibata, "Impedance and photoelectrochemical properties of porous oxide film on Type304 stainless steel formed by square wave potential pulse polarization," Journal of Electroanalytical Chemistry, vol. 473, no. 1, pp. 265-271, 1999.

[3] A. M. P. Simões, M. G. S. Ferreira, G. Lorang, and M. da Cunha Belo, "Influence of temperature on the properties of passive films formed on AISI 304 stainless steel," Electrochimica Acta, vol. 36, no. 2, pp. 315-320, 1991.

[4] Y. S. Zhang, X. M. Zhu, M. Liu, and R. X. Che, "Effects of anodic passivation on the constitution, stability and resistance to corrosion of passive film formed on an $\mathrm{Fe}-24 \mathrm{Mn}-4 \mathrm{Al}-5 \mathrm{Cr}$ alloy," Applied Surface Science, vol. 222, no. 1-4, pp. 89-101, 2004.

[5] Z. Chen, C. Xu, N. Huang, X. Shi, S. Hu, and T. Zhang, "A study on the anodically passivated film of sus36 stainless steel," Journal of Chinese Society for Corrosion and Protection, vol. 11, no. 2, pp. 125-131, 1991.

[6] S. L. Gojkovic, S. K. Zecevic, and D. M. Drazic, "Oxygen reduction on iron-Part VI. Processes in alkaline solutions," Electrochimica Acta, vol. 39, no. 7, pp. 975-982, 1994.

[7] R. Kirchheim, B. Heine, H. Fischmeister, S. Hofmann, H. Knote, and U. Stolz, "The passivity of iron-chromium alloys," Corrosion Science, vol. 29, no. 7, pp. 899-917, 1989.

[8] I. Olefjord, B. Brox, and U. Jelvestam, "Surface composition of stainless steels during anodic dissolution and passivation studied by ESCA," Journal of the Electrochemical Society, vol. 132, no. 12, pp. 2854-2861, 1985.

[9] J. E. Castle and J. H. Qiu, "A co-ordinated study of the passivation of alloy steels by plasma source mass spectrometry and x-ray photoelectron spectroscopy-1. characterization of the passive film," Corrosion Science, vol. 29, no. 5, pp. 591-603, 1989.

[10] D. D. Macdonald, "On the tenuous nature of passivity and its role in the isolation of HLNW," Journal of Nuclear Materials, vol. 379, no. 1-3, pp. 24-32, 2008.

[11] D. D. MacDonald, "On the existence of our metals-based civilization I. Phase-space analysis," Journal of the Electrochemical Society, vol. 153, no. 7, pp. B213-B224, 2006.
[12] D. D. Macdonald, K. M. Ismail, and E. Sikora, "Characterization of the passive state on zinc," Journal of the Electrochemical Society, vol. 145, no. 9, pp. 3141-3149, 1998.

[13] D. D. Macdonald, S. R. Biaggio, and H. Song, "Steady-state passive films. Interfacial kinetic effects and diagnostic criteria," Journal of the Electrochemical Society, vol. 139, no. 1, pp. 170177, 1992.

[14] D. D. Macdonald, "Point defect model for the passive state," Journal of the Electrochemical Society, vol. 139, no. 12, pp. 3434-3449, 1992.

[15] D. D. Macdonald and S. I. Smedley, "An electrochemical impedance analysis of passive films on nickel(111) in phosphate buffer solutions," Electrochimica Acta, vol. 35, no. 11-12, pp. 1949-1956, 1990.

[16] A. Fattah-alhosseini, A. Saatchi, M. A. Golozar, and K. Raeissi, "The transpassive dissolution mechanism of 316L stainless steel," Electrochimica Acta, vol. 54, no. 13, pp. 3645-3650, 2009.

[17] A. Fattah-Alhosseini, A. Saatchi, M. A. Golozar, and K. Raeissi, "The passivity of AISI 316L stainless steel in 0.05 M HSO," Journal of Applied Electrochemistry, vol. 40, no. 2, pp. 457-461, 2010.

[18] A. Fattah-alhosseini, M. A. Golozar, A. Saatchi, and K. Raeissi, "Effect of solution concentration on semiconducting properties of passive films formed on austenitic stainless steels," Corrosion Science, vol. 52, no. 1, pp. 205-209, 2010.

[19] J. M. Blengino, M. Keddam, J. P. Labbe, and L. Robbiola, "Physico-chemical characterization of corrosion layers formed on iron in a sodium carbonate-bicarbonate containing environment," Corrosion Science, vol. 37, no. 4, pp. 621-643, 1995.

[20] V. H. Radosevic, K. Kvastek, D. Hodko, and V. Pravdić, "Impedance of anodically passivated FeB over potentials from passive state to oxygen evolution," Electrochimica Acta, vol. 39, no. 1, pp. 119-130, 1994.

[21] M. Gaberscek and S. Pejovnik, "Impedance spectroscopy as a technique for studying the spontaneous passivation of metals in electrolytes," Electrochimica Acta, vol. 41, no. 7-8, pp. 11371142, 1996.

[22] E. B. Castro and J. R. Vilche, "Investigation of passive layers on iron and iron-chromium alloys by electrochemical impedance spectroscopy," Electrochimica Acta, vol. 38, no. 11, pp. 15671572, 1993.

[23] H. H. Ge, G. D. Zhou, and W. Q. Wu, "Passivation model of 316 stainless steel in simulated cooling water and the effect of sulfide on the passive film," Applied Surface Science, vol. 211, no. 1-4, pp. 321-334, 2003.

[24] M. A. Ameer, A. M. Fekry, and F. E. T. Heakal, "Electrochemical behaviour of passive films on molybdenum-containing austenitic stainless steels in aqueous solutions," Electrochimica Acta, vol. 50, no. 1, pp. 43-49, 2004.

[25] S. Ningshen, U. K. Mudali, G. Amarendra, P. Gopalan, R. K. Dayal, and H. S. Khatak, "Hydrogen effects on the passive film formation and pitting susceptibility of nitrogen containing type 316L stainless steels," Corrosion Science, vol. 48, no. 5, pp. 1106-1121, 2006.

[26] D. Wallinder, J. Pan, C. Leygraf, and A. Delblanc-Bauer, "EIS and XPS study of surface modification of 316LVM stainless steel after passivation," Corrosion Science, vol. 41, no. 2, pp. 275-289, 1998.

[27] J.-B. Lee, "Effects of alloying elements, Cr, Mo and N on repassivation characteristics of stainless steels using the abrading electrode technique," Materials Chemistry and Physics, vol. 99, no. 2-3, pp. 224-234, 2006. 
[28] J. Jamnik, J. Maier, and S. Pejovnik, "Powerful electrical network model for the impedance of mixed conductors," Electrochimica Acta, vol. 44, no. 24, pp. 4139-4145, 1999.

[29] N. Priyantha, P. Jayaweera, D. D. Macdonald, and A. Sun, "An electrochemical impedance study of alloy 22 in $\mathrm{NaCl}$ brine at elevated temperature. I. Corrosion behavior," Journal of Electroanalytical Chemistry, vol. 572, no. 2, pp. 409-419, 2004.

[30] B. D. Cahan and C. T. Chen, "The nature of the passive film on iron. III. The chemi-conductor model and further supporting evidence," Journal of the Electrochemical Society, vol. 129, no. 5, pp. 921-925, 1982.

[31] L. Hamadou, A. Kadri, N. Benbrahim, and J. P. Petit, "Characterization of thin anodically grown oxide films on AISI 304L stainless steel," Journal of the Electrochemical Society, vol. 154, no. 12, pp. G291-G297, 2007.

[32] D. Qu, "Application of a.c. impedance technique to the study of the proton diffusion process in the porous $\mathrm{MnO}_{2}$ electrode," Electrochimica Acta, vol. 48, no. 12, pp. 1675-1684, 2003.

[33] E. Sikora and D. D. Macdonald, "Nature of the passive film on nickel," Electrochimica Acta, vol. 48, no. 1, pp. 69-77, 2002. 


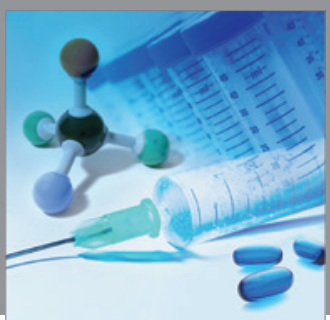

International Journal of

Medicinal Chemistry

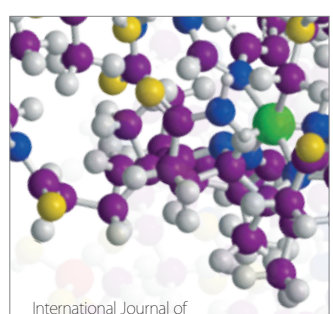

Carbohydrate Chemistry

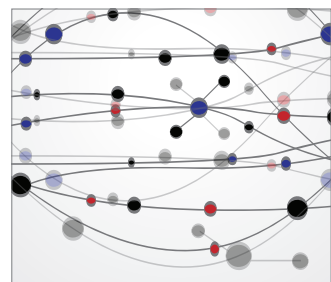

The Scientific World Journal
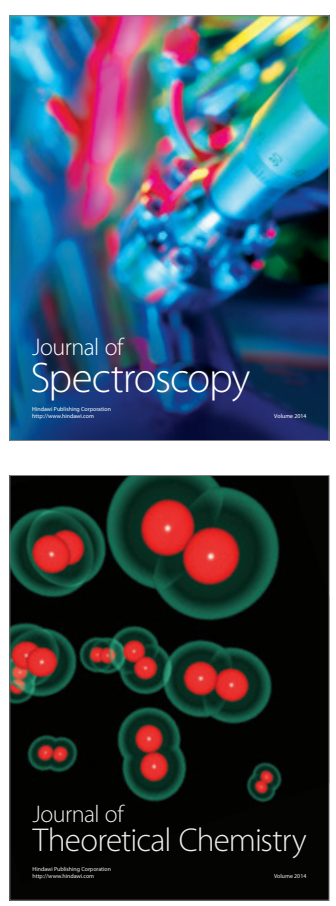
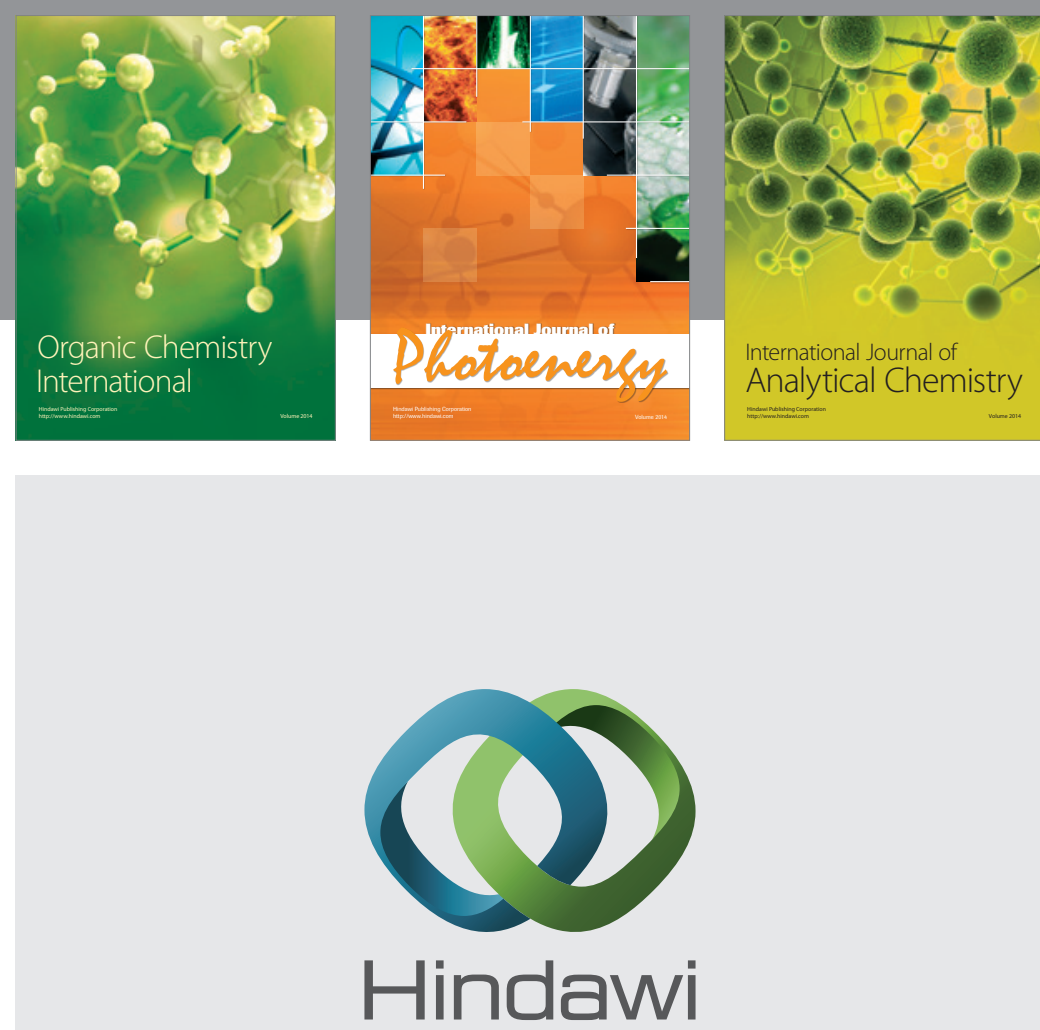

Submit your manuscripts at

http://www.hindawi.com
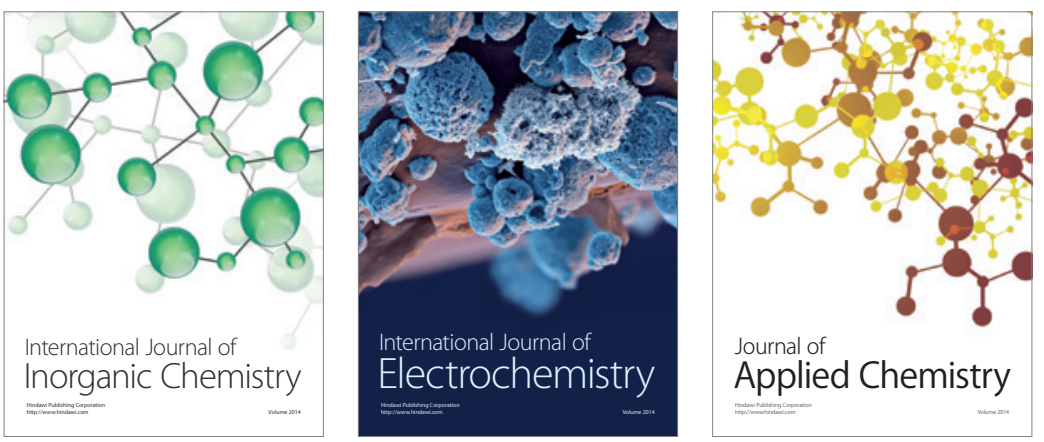

Journal of

Applied Chemistry
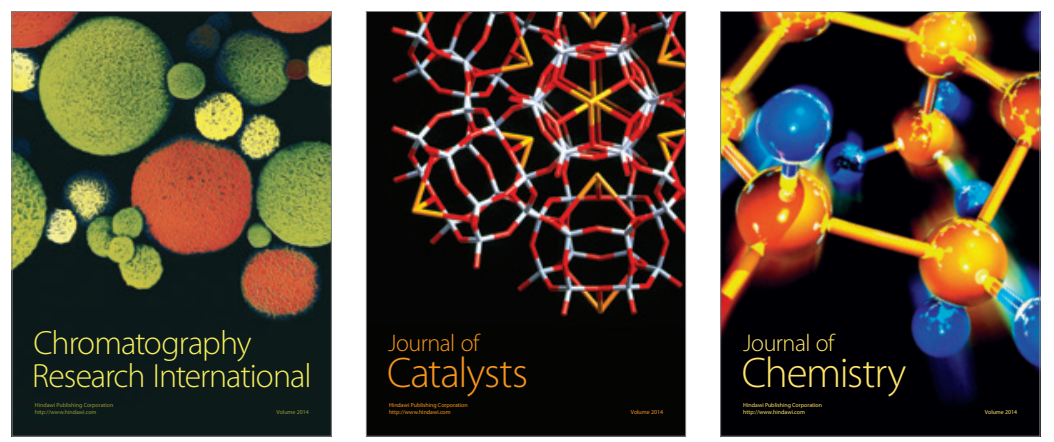
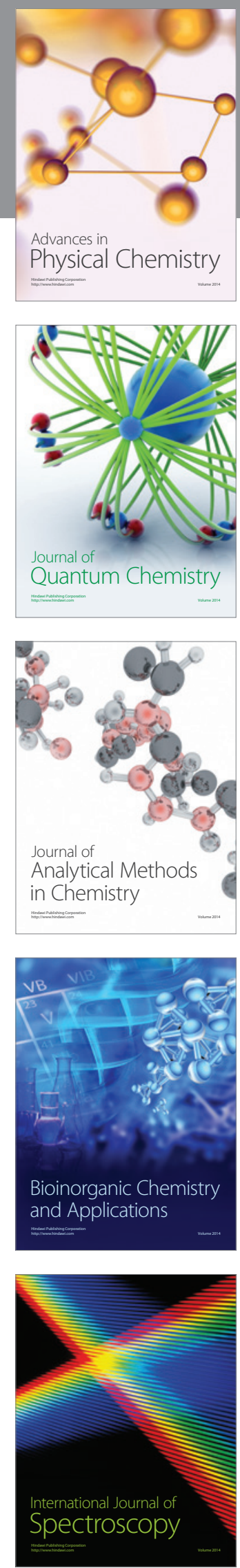